Send your letters to the Editor,

British Dental Journal

64 Wimpole Street

London

W1G 8YS

E-mailbdj@bda.org

Priority will be given to letters less than 500 words long.

Authors must sign the letter, which

may be edited for reasons of space.

\section{EXPRESSING CONSENT}

Sir, we read with interest the article regarding Continuous consent and dignity in dentistry (BDJ 2007; 203: 569571). As there has been an axiomatic shift from a paternalistic to a patientcentred healthcare model, it is indeed pertinent to have this debate.

The author proposed three questions in his article which we feel warrant a response. In summary he asked:

- If consent is obtained only at the beginning of an intervention, is it truly continuous?

- Can the problem of inarticulable withdrawal of consent be solved?

- Can violation of patient autonomy, however slight, be avoided?

We feel there are practical solutions to patient management which may provide satisfactory answers to these queries, examples of which we provide below.

Expressed consent must be gained prior to the commencement of any intervention and, as applies to a medical history, reconfirmed and recorded at each visit. At an early stage it would also be prudent to agree a non-verbal 'stop signal' (eg a raised hand) should the occasion arise in which a patient wishes to withdraw that consent, however temporarily. This simple tool would obviate the need to rely on a verbally expressed revocation and in doing so allow the patient to maintain control over their body.

We believe that applying these simple techniques would render the consent process both valid and continuous, thus avoiding violation of patient autonomy.

R. Nansi

A. Ray-Chaudhuri Birmingham
David Shaw, the author of the article, responds: I appreciate the response from R. Nansi and A. Ray-Chaudhuri regarding my article on consent. I quite agree that consent should be reconfirmed and recorded at each visit to the dental practice, but am not convinced by their other main point.

Nansi and Ray-Chaudhuri suggest that stop signals could solve the problems highlighted in my paper. However, my point was that signals don't always work, particularly if the dentist is leaning close to the patient; I actually wrote that in one case 'I wanted my dentist to withdraw, but she didn't notice'. It is not just that dialogue is usually impossible during an intervention, but also that some attempted physical indications of withdrawal of consent fail.

Stop signals can certainly help to avoid some violations of patients' autonomy, but the fact remains that dental patients are often put in situations where withdrawing consent is difficult. This is far from ideal, and guidelines should acknowledge and address the particular difficulties involved in obtaining and maintaining consent in dental practice.

DOI: 10.1038/bdj.2008.56

\section{TONGUE POSTURE}

Sir, I would like to congratulate Drs Noble, Caraiskos and Wiltshire for their paper on this subject (BDJ 2007; 203: 632-634) and in particular on mentioning the word 'tongue' when considering infra-occlusion. So many clinicians fail to consider tongue posture, primarily because it is almost impossible to measure and therefore little evidence is available.

The presence of a lateral openbite of the type shown by the authors is not uncommon in the early mixed dentition but its initial development often passes unobserved. The deciduous molars are nearly always in occlusion until the first molars erupt, but if the tongue rests over the surface of the deciduous molars, a posture that is common within many civilised populations, then the permanent molars may erupt into occlusion behind them creating a lateral open bite.

It is usually easy to demonstrate this by removing the permanent molars from the plaster models and observing that the deciduous teeth occlude naturally. Obviously it is important to correct or at least improve the tongue posture and various measures such as expansion to create more room or postural training have been in use for years but generally this has not been popular amongst orthodontists in the UK and USA.

$$
\begin{array}{r}
\text { J. Mew } \\
\text { By email } \\
\text { DOI: } 10.1038 / \text { bdj. } 2008.57
\end{array}
$$

\section{SUPERFLUOUS DISCLAIMER}

Sir, I write in response to the review article by D. J. Perry et al., Guidelines for the management of patients on anticoagulants requiring dental surgery (BDJ 2007; 203: 389-393).

A feature in the article raises an important issue which if not tackled, may set a bad and dangerous precedent. I have issue with the disclaimer at the end of the article. I can only presume that the authors are worried that should the information in their article be relied on to the detriment of readers, they (the authors) could be held liable for negligence or negligence misstatement and that the disclaimer has therefore been inserted to exclude such liability. Should 
a scientific article to be published carry a disclaimer? In my opinion, except in certain circumstances ${ }^{1}$ the answer is no for the following reasons.

First, the authors' anxiety is without foundation. In what circumstances would duty be imposed? Where authors, putting themselves out as having special skill or knowledge, voluntarily assume the responsibility (either gratuitously or for payment) to give advice to a client; where that client knows that the information would be communicated to him for a purpose; and where the authors know that the client would rely on the advice or information for that purpose, for which harm is reasonably foreseeable, except in the absence of a disclaimer, it may be just and reasonable to impose a duty to exercise reasonable care and skill.

It is submitted that the situation for these authors is entirely different. Their article may be repeated endlessly with or without their permission and may be relied on in a different way by different readers to their detriment. Since the $B D J$ is read worldwide, should the authors be held liable for all readers (potential claimants)? English law has imposed some intelligent limits to keep the law of negligence within common sense and practicality. Those limits are the requirements that there is 'a relationship of proximity' between the authors and readers/potential claimants for harm suffered on reliance on an article; and that the attachment of liability for the harm that may occur be 'just and reasonable'. ${ }^{2}$

Yes, harm may be foreseeable but to people whom the authors have no specific reason to anticipate. Clearly to hold the authors to be under duty of care in respect of the accuracy of their article to all and sundry for any purpose is to subject them to 'liability in an indeterminate amount for an indeterminate time to an indeterminate class. ${ }^{3}$

Second, the information in the review article is already in the public domain, including equally good reviews articles but without disclaimers. ${ }^{4-7}$ The authors, in essence have not produced an original piece of work, are therefore repeating 'notorious facts' and therefore cannot disavow a claim they simply do not have.
We should not lose sight of the mission statement of the $B D J$ (which mirrors that of other reputable scientific journals) which is to inform its readers of ideas, opinions, developments and the key issues in dentistry...' Prospective authors should be confident in the settled law. A disclaimer is not necessary and serves no real purpose.

\section{S. Appiah-Anane} Liverpool

Note: The article was not commissioned by the $B D A$ (for its members and/or readers of the $\mathrm{BDJ}$ ) from the authors. The Hedley Byrne principle does not apply to impose duty on the authors.

1. Hedley Byrne \&t Co Ltd v Heller \&t Partners [1964] AC 465, HL; [1963] 2 All ER 575, HL. See also the dissenting judgment of Denning $L J$ in Candler v Crane Christmas \&t Co [1951] 1 All ER 426, CA approved and applied in Hedley Byrne.

2. Caparo Industries plc v Dickman [1990] 1 All ER 568, HL.

3. Ultramares Corp v Touche (1931) 255 NY 170 at 179, NY Ct of Apps. per Cardozo CJ.

4. Evans I L et al. Can warfarin be continued during dental extractions? Br J Oral Maxillofac Surg 2002; 40: $248-252$

5. Dodson T B. No need to routinely discontinue anticoagulants before dental extractions. Evid Based Dent 2003: 3: 100-101.

6. Dodson T B. Managing anticoagulated patients requiring dental extractions: an exercise in evidence-based clinical practice. Evid Based Dent 2002; 3: 23-26.

7. North West Medicines Information Centre Pharmacy Practice Unit Surgical management of the primary care dental patient on warfarin (July 2001).

\section{DOI: $10.1038 /$ bdj.2008.58}

\section{BACKGROUND EXPECTANCIES}

Sir, as an example of the beauty of background expectancies this one always makes me giggle.

A few years ago, whilst discussing career options with my practice manager I said to her 'It's about time I moved on and did a house job' to which she replied 'yes, good idea, buy yourself a little house and do it up', which received raucous laughter!

Come to think of it, she made sense; perhaps I should become a property developer!

\section{T. Crandon \\ Bridgend \\ DOI: $10.1038 /$ bdj.2008.59}

\section{AN ACTIVE BRAIN}

Sir, the time will come, though fortunately not yet, when I have to address the question of when to retire.

As a Senior Registrar, I remember being addressed by my Senior Consultant with the advice that we should continue reading all the dental journals until ten years before our retirement.

May I take this opportunity of offering somewhat different advice?

We should all continue our personal clinical audits of patient management, clinical diagnosis and treatment standards. To carry out such an audit conscientiously requires the maintenance of an active brain. Without doubt, maintenance of such intellectual activity is stimulated by reading our journals.

As soon as we are individually not prepared to continue such critical selfclinical analysis, then is the day to retire and it is also the day that one can reasonably cease perusing our excellent journals.

B. Littler

Chelmsford

DOI: 10.1038/bdj.2008.60

\section{HYGIENIST-THERAPIST REMIT}

Sir, I was interested to read the letter from D. G. Hillam (Silent revolution, BDJ 2008 ; 204: 4-5) regarding the paper by Jones et al. (BDJ 2007; 203: 524-525) which discussed the attitudes of dentists in Wales towards dually qualified dental hygienist-therapists. This work reiterated the findings of our earlier research gathered from a sample of dentists in South East Scotland.

It appears that much ignorance exists regarding the clinical remit of dually qualified dental hygienist-therapists and until this is addressed, suspicion arising from this lack of knowledge will undoubtedly persist. Firstly, we have to remind ourselves that the new generation of dental therapists also hold a qualification in dental hygiene, and are therefore dually qualified individuals. Their skills are extensive from a preventive, periodontal and restorative perspective. Furthermore, it is estimated that they can undertake $70 \%$ of routine dentistry amongst both the adult and child population.

A 'simple filling' as referred to by your correspondent can be defined as that which does not involve the adult pulp, or require the services of a dental laboratory. In addition to being able to treat advanced periodontal disease, dually qualified hygienist-therapists 
are trained to a very high standard to undertake many 'routine' restorative procedures. Indeed, it could be argued that significantly more time is spent by these individuals in doing more 'routine dentistry' than many an undergraduate in the UK because of the more limited nature of their clinical remit. This is certainly the case in the treatment of periodontal disease where even in an integrated hygiene-therapy programme, the practical experience gained is far greater.

D. G. Hillam states that some hygienist-therapists "will push to the legal limits or even further, with or without the blessing of a dentist who may be unclear of the regulations'. This implies that these fully trained, qualified and statutorily registered dental professionals, who are only too aware of their clinical remit, may contemplate undertaking illegal practice. Law, ethics and professionalism are a significant component of the curriculum and indeed, the specific learning outcomes relating to this detailed in the curricula for both BDS undergraduates and DCPs are almost identical. There is no reason therefore to suggest that hygienisttherapists would have any less rigorous ethical standards than dentists, given they are subject to the same disciplinary procedures.

Your correspondent is inaccurate in observing that DCPs could 'undertake the business of dentistry sometime in the future'. This has been the case since July 2006 when they were also permitted to set up in practice, albeit operating via a referral system, or by employing a dentist who would see the patient for an initial examination. To suggest that 'quality, safe dentistry' may not be provided by hygienist-therapists is unreasonable. They are taught how to act in the best interest of the patient by making appropriate referrals should they find something which is beyond their clinical competence to treat, or where they recognise any abnormal lesions which give them cause for concern.

Mr Hillam goes on to state that 'therapist training has been at the expense of that for hygienists'. The curriculum for either a singly-qualified hygienist or a dually-qualified hygienist-therapist is identical and time spent developing hygienist and therapist skills are comparable with each other. It is also disappointing to note that Mr Hillam states that 'hygienists play a major role in assisting the dentist in the management of periodontal diseases'. This paints a rather subsidiary picture of the hygienist, instead of recognising their significant clinical expertise. Surely, given that the training a hygienist or hygienisttherapist receives in periodontal therapy is vastly greater than an undergraduate, they can do rather more than just 'assist' the dentist in this treatment?

Recent, but as yet unpublished, work we have undertaken in Scotland investigated final year dental undergraduates' course-based experience of teamworking, and their knowledge and attitudes towards the clinical remit of hygienists and hygienist-therapists. It became evident very quickly that many undergraduates knew little of the remit of other individuals and held them in low esteem, which was very disheartening, given they were coming to the end of their training. It is vital that each member of the dental team is aware of the clinical responsibility of each other as stated in the First five years and that professional knowledge and respect is encouraged at an early stage.

Dentistry has lagged behind medicine in terms of recognising the skills and abilities of all members of the team. In medicine, nurse practitioners, nurse consultants and nurse specialists exist and function effectively and efficiently alongside doctors in both the primary and secondary care setting. Those in dentistry should be encouraged to embrace change which has not evolved by chance, but by the realisation that it is time to move away from the hierarchical system which has reigned in our profession for too long. The oral health of the population is the concern of all dentists and dental care professionals, and by working in tandem we may make progress in addressing the unacceptable levels of disease which continue to exist in the UK.

M. K. Ross

Senior Lecturer for DCP

Edinburgh

DOI: $10.1038 /$ bdj.2008.61 


\section{BRILLIANT CONTROL}

Sir, in your Editor's summary (BDJ 2007; 203: 468) with regard to the research paper on steam sterilisers, you ask the question, '...if, demonstrably these rightly exacting, evidence-based standards are not being universally upheld when might we, very embarrassingly, start to see evidence-base of this and its effects?'

Surely if the sterilisation methods which have been current for many years (some of which are obviously not adequate) have been so ineffective then why is the dental profession not being hounded for the vast number of infections it is supposed to be transmitting to all and sundry who dare to visit our surgeries? Where is the evidence of our failure?

I think the standards we have now have vastly improved in the 35 years that I have been in practice but where, please, is the evidence that we are causing any major or minor outbreaks of infection through patients coming to our surgeries? The number of patients I talk to and friends who I know personally who have had hospital acquired infections makes one worried about any hospitalisation. Are we all on tenterhooks waiting for a similar outbreak in our patients?

As I see the evidence, our infection control is brilliant compared with the NHS hospital system and we should be congratulated on the hard work that has been done. Finally what real difference is it going to make if we all, 100\%, have 'procedures for the identification and traceability of instruments used on patients'? Will it really put a stop to all the infections we are supposed to be spreading around?

S. C. Bazlinton

Dunmow

DOI: 10.1038/bdj.2008.62

\section{FACEMASKS}

Sir, the discussion of cross infection measures in the interesting paper by McKenna et al. (BDJ 2007; 203: 681685) gives possible reasons for the older generation's dislike of facemasks compared to the younger generation. Another explanation could be offered in that gradual hearing loss in this age group occurs frequently. Subconscious lip reading is common and facemasks covering the lips prevent proper communication during treatment, causing the older patient to feel inadequate and unable to respond to surgery staff.

L. Davis

Sheffield

DOI: $10.1038 /$ bdj.2008.63

\section{POOR ENGLISH}

Sir, two of the 17 conduct cases reported in the latest GDC Gazette involved dentists whose poor understanding of English appeared to be a contributory factor in their problems.

If their English was so poor, how did they achieve registration in the first place?

\section{Forsyth} Rutland

DOI: 10.1038/bdj.2008.64

\section{ZIMBABWE DONATIONS}

Sir, may I through your pages make the following appeal to colleagues/dental companies/dental institutions for the donation of any redundant or unused dental equipment or materials they may have for use by the dental students and the Dental School in Zimbabwe. Anything will be a tremendous gift - dental materials, cements, impression materials, alginates, handpieces, burs, impression trays, forceps, elevators, ultrasonic scalers, dental equipment (220-240V).

Please forward all donations to my practice address as follows:

Hendrik DeWaal

Specialist Periodontics Centre

1600 High Street

Knowle nr. Solihull

B93 OLF

Tel/Fax: 01564771703

Email: hendrikdewaal@aol.com

I will make sure they are forwarded and will arrive in the right hands for the right people. The hardworking dental students really need our help.

$$
\begin{array}{r}
\text { H. DeWaal } \\
\text { By email } \\
\text { DOI: } 10.1038 / \text { bdj.2008.65 }
\end{array}
$$

\section{NO CHOICE}

Sir, I, like hopefully all of my colleagues, have just paid the ARF to allow us to continue practising dentistry for the coming year. Probably like many others, it took the reminder to encourage me to pay! The 24/7 telephone number for credit card payments was apparently only valid during office hours so I decided to pay over the Internet. The transaction was quick and simple and I could print out a receipt to prove that I had paid before the year end.

What a surprise it was to be contacted three weeks later by Google thanking me for my recent 'purchase' from the GDC and asking me to rate and review my experience on a one to five star rating:

5 stars - 'Excellent; I would definitely buy from this seller again'

1 star - 'Poor; I would discourage other users from buying from this seller'.

I would have liked to have answered truthfully by rating with 1 star but unfortunately, as I wish to continue to practise dentistry, I have got no bloody choice!

\section{A. Stubley \\ By email}

DOI: $10.1038 /$ bdj.2008.66

\section{AUTOCLAVE MEALS}

Sir, with reference to Root treatment (BDJ 2007; 203: 669) you may be interested to learn that, in future, the television chefs will no longer be able to bake, boil, roast, steam or stew their goods - it will all have to be autoclaved.

D. L. S. Shinn Guildford DOI: 10.1038/bdj.2008.67 